Cad. Benjaminianos, Belo Horizonte, v. 15, n. 2, p. 75-90, 2019

\title{
Fiama Hasse Pais Brandão e Walter Benjamin: poesia, ruína e aura
}

\section{Fiama Hasse Pais Brandão and Walter Benjamin: Poetry, Ruin and Aura}

\section{Fernanda Drummond}

Universidade Federal do Rio de Janeiro (UFRJ), Rio de Janeiro, Rio de Janeiro / Brasil fernandadrummond@gmail.com

João Vilhena

vilhena.jc@gmail.com

Resumo: Este artigo recorre ao conceito de aura e à alegoria do Anjo da História de Walter Benjamin para explorar como a obra de Fiama Hasse Pais Brandão comunica com o pensamento pensador alemão. Em Fiama, o sujeito poético recusa o fluxo contínuo do tempo, posicionando-se num «Agora» atemporal, que se sustenta das ruínas do passado e da destruição vindoura. Avessa como Benjamin à ideia de progresso, Fiama invoca uma tradição dinâmica e heterodoxa, mostrando-nos como o mundo não é mais que a vidraça onde embatem as palavras dos mortos. Palavras que junto com a experiência do sujeito poético no seu mundo possibilitam uma recuperação da aura nos objectos observados a partir de uma distância contemplativa. A utilização do quadro teórico de Benjamin permite ainda detectar uma dimensão política geralmente pouco discutida na obra de Fiama Hasse Pais Brandão.

Palavras-chave: Poesia Portuguesa Contemporânea; Poesia 61; Fiama Hasse Pais Brandão; Walter Benjamin; ruína

Abstract: This article uses Benjamin's concept of aura and his Angel of History allegory to investigate how a reading of Fiama Hasse Pais Brandão's work can be enriched by the thought of the German philosopher. In Fiama's poetry, the lyrical subject refuses the continual flow of time by assuming an out-of-time "Now", a position that is sustained by the ruins of the past and the incoming destruction which threatens that same "Now". As Benjamin, Fiama opposes the idea of progress, while evoking a dynamic and heterodox tradition, to reveal us the world as a mere window pane into which the words of the 
dead poets collide. These words retrieved from the ruins of human culture combine with the world as experienced by the lyrical subject to produce a configuration where it is possible to recover the aura in objects observed from a contemplative distance. We further argue that the use of Benjamin's theory allows us to unveil a usually overlooked political dimension which nonetheless present within Fiama's body of work.

Keywords: Contemporary Portuguese poetry; Poesia 61; Fiama Hasse Pais Brandão; Walter Benjamin; ruins.

\section{O tempo, os detritos, o lodo no bojo}

A poesia da poeta portuguesa Fiama Hasse Pais Brandão surge no contexto dos anos 1960 num Portugal assolado pela ditadura salazarista. Muitas vezes foi chamada de hermética quando precisava buscar uma opacidade que pudesse driblar o sistema de censura das obras de arte. Não obstante esse empecilho, a escrita que desenvolveu ao longo de 50 anos de vida literária se mostra capaz de movimentar acepções em "estado dicionário", ou seja, cristalinas, assim como cria novos recursos para decodificar as imagens e palavras que aborda. Nos títulos de seus poemas encontramos os seguintes recursos classificatórios: sumários ("Sumário Lírico"), teorias ("Teoria da Realidade, tratando-a por tu”), catálogos ("Catálogo botânico da primavera"), enumerações ("Enumeração da vista e do ouvido"), os quais, numa linguagem que se apropria do científico e da listagem, procuram pôr em evidência o "enigma da Imagem", como diz o poema "Peregrinação e Catábase", do livro Cenas Vivas (2000):

O homem (...)

é ateu, mas ama os dons do espírito

que põem na Imagem a sua aura.

Imagem de face rósea e branca fronte,

de olhar de porcelana, sempre fixo, mas móvel e amante, tanto quanto o amor

do Peregrino Só e dos peregrinos

deseja aquele olhar sobre o seu peito.

A Imagem era um enigma que sorria

para o Peregrino. (BRANDÃO, 2006, p. 684)

Walter Benjamin pode ser visto como esse "homem ateu" que "ama o espírito" - sobretudo se pensarmos na influência que Kant teve em sua filosofia. Ademais, o poema afirma que esse espírito, o conhecimento, 
"põe na Imagem a sua aura". Central para o pensamento benjaminiano, o conceito de aura na obra de arte pode ser explicado como "a aparição única de algo distante" (KOTHE, 1972, p. 39). Na perspectiva de Fiama, o deslocamento, obrigatório para o personagem do "Peregrino", que domina o poema, é o caminho necessário para alcançar o enigma. Por mais que em Benjamin a imagem da aura esteja num contexto de destruição ou perda, de desaparecimento motivado pela reprodutibilidade técnica, nesse poema existe uma vontade de restaurá-la de maneira positiva, através da peregrinação e do mergulho no interior das imagens. Elas se mostram como móveis, e, assim sendo, nunca se distanciam do olhar do peregrino, movimentando-se com ele: "o olhar (...) sempre fixo, mas móvel e amante, tanto quanto o amor do Peregrino" (BRANDÃO, 2006, p. 684). Dessa forma, na medida que esse intérprete faz seu percurso conforme a imagem olhada, ela se move com ele na sua caminhada, não está mais distanciada.

Dessa maneira, a relação espaço-temporal neste poema da poeta portuguesa assume um papel de bastante intimidade, como se a imagem do Peregrino, ao mesmo tempo que o associasse centralmente à sua própria presentificação, o desassociasse do fluxo da ordem dos acontecimentos, numa disrupção narrativa. É essa cristalização do momento fora do fluxo contínuo da História em Fiama que devolve a aura ao objeto, e à experiência. Em "Peregrinação e Catábase", para presentificar o tempo passado, o sujeito projecta-se na memória da criança que ele foi. Volta-se a um tempo passado da sua história, sendo agora a Criança quem guia o Peregrino ao longo dos sintomas de destruição do século. Volta-se à infância para recuperar as imagens das ruínas, reveladas no momento histórico. Essa sincronia entre dois pontos diacrónico é constantemente renovada de forma explícita na sua poesia.

No poema "Modo histórico da cidra", reproduzido na íntegra abaixo, o eu poético auratiza o fruto, fazendo-o irromper destacado da ligação com o evento histórico que o representa: o aniversário da poeta, que, não inadvertidamente, figura na data transcrita abaixo do poema, em letra menor. Desta forma, o nascimento do fruto, "cidra", no segundo verso, coincide com o nascimento da poeta: "num tempo celebrado, o aniversário" - uma citação indireta do poema pessoano "Aniversário". 


\section{MODO HISTÓRICO DA CIDRA}

Numa lápide, afinal, num puro tampo (de mesa), um ente nasce:

o fruto (diáfano); cidra, em si a sua origem;

vem do tempo, celta ou da ibéria, já

me transcende?

Ó reino pressuposto de um

vegetal; essa paragem - cidra - no percurso.

Num tempo celebrado, o aniversário.

É um suco mortífero, ou o de um real aberto porque o vêem muitos modos ou o dizem.

Meus anos expostos (a frutos) que formas

confirmaram; ou, mais longínquo, houve o soalho; no espaço a hora ocorre.

A omissão de cidra ou mármore ágrio é um dom

do luto: meu exercício e o mundo.

E que urna ou ornamento (essa mesa)? É

um sentido vário; não que pereça,

mas, quando imóvel, muda. A emoção de ser

corpo (um fruto) decomposto que hoje

recrio ou lego: a minha existência

(entre os iberos) urge.

\section{Agosto 69}

(BRANDÃO, 2006, p. 144)

A questão da ruína, também benjaminiana por excelência, aparece aqui sob a regência do que "perece" e "muda" (estrofe 3, v. 2 e 3), uma vez imóvel, além da presença de um corpo/fruto que se "decompõe" (estrofe 3, v. 4).

A aura é recuperada apesar da ruína da vida, da passagem tempo, das "barcas com armas", 1 dos trabalhadores agonizantes sob "tectos baixos". ${ }^{2}$

${ }^{1}$ Cf. "Lisboa tem barcas/ agora lavradas de armas// [...] Barcas novas levam guerra/ As armas não lavram terra" (BRANDÃO, 2006, p. 31), no poema "Barcas Novas", do livro homônimo de 1967, em plena Guerra Colonial pela posse do território ultramarino português.

${ }^{2}$ Cf. "O ar e os tectos": "e nós sem profissões libertas, também/ a erguer os corpos/ opressos pelos tectos" (BRANDÃO, 2006, p. 78-79). 
Há uma narrativa, um percurso, no qual o poema constitui uma paragem. A cidra, resultado da acção da cultura humana sobre um fruto, ele já uma forma domesticada de natureza, cidra, o suco do tempo. O poema destrói a imobilidade do que está pousado sobre a mesa. Tudo é já a sua metamorfose. A poeta cria esse encontro no narrar do seu poema, "a passagem do canto real ao canto imaginário", como diz Blanchot n' $O$ livro por vir. (BLANCHOT, 2016, p. 11), ou ainda "o próprio tempo da metamorfose" (BLANCHOT, 2016, p. 11). O percurso leva-nos aonde? À consciência aguda da urgência do tempo, da plenitude da transformação, o aniversário é já a urna, sobre a mesa, imóveis, as coisas morrem, leva a poeta "ao ponto onde cantar deixará de ser um logro" (BLANCHOT, 2016, p. 11), pois o cantar recria o percurso da ruína. É na aparente imobilidade do poema, que, ao narrar, o poeta se transforma, se encontra com um tempo que está por vir, repetição da morte vista nos seres, nas paisagens. Nesse paradoxo temporal, a poeta pode exaltar a emoção de ver a sua própria ruína, de a transformar numa espécie de cristal nutrido pelo tempo, que pela sua existência nas palavras a poeta lega aos vivos: "A emoção de ser corpo (um fruto) decomposto / que hoje recrio ou lego: a minha existência / (entre os iberos) urge".

\subsection{A história da mão que lavra, faz o pão, alinha os fusos, separa as águas e o sol}

Outro aspecto que parece aproximar a obra de Fiama do pensador alemão é a valorização da herança cultural, que Benjamin via como uma resistência à perda de autenticidade do objecto. A reprodutibilidade seria responsável pela "liquidation of the traditional value of the cultural heritage" (BENJAMIN, 1992, p. 211). Uma obra de arte é, de acordo com Benjamin, única e singular por se inserir numa tradição, mas esta tradição é "thouroughly alive and extremely changeable" (BENJAMIN, 1992, p. 244). Veja-se como a poeta portuguesa cria o seu próprio cânone individual ou recorre à tradição cabalística medieval para activar novos sentidos na leitura de Camões, ${ }^{3}$ inserindo-o num novo contexto, afastado das apropriações tradicionalistas e nacionalistas empoladas desde o século XIX e reaproveitadas pela ideologia fascista, porém próximo dos anseios políticos da sua época, marcando esses movimentos revolucionários que

\footnotetext{
${ }^{3}$ Leituras presentes nos ensaios de Fiama sobre a cultura portuguesa em $O$ labirinto camoniano e outros labirintos (1985).
} 
não aparecem como evidentes ao longo da sua obra, em particular se os lermos na óptica das teses sobre o conceito de história (as citações a que recorremos aqui são da tradução inglesa: Theses on the Philosophy of History, 1992).

Não esqueçamos que a proposta estética de Benjamin contém uma forte dimensão política, como atestado nas palavras finais do prefácio do seu famoso ensaio sobre a reprodutibilidade técnica: "The concepts which are introduced in the theory of art in what follows differ from more familiar terms in that they are completely useless for the purposes of Fascism. They are, on the other hand, useful for the formulation of revolutionary demands in the politics of arts" (BENJAMIN, 1992, p. 212). Uma leitura da obra da Fiama pelo prisma crítico benjamiano permite analisar uma dimensão política na obra da poeta portuguesa, muitas vezes ignorada, apesar de ter surgido no contexto ao qual já nos referimos. Recuperando o epílogo do ensaio do pensador, podemos ler a visão de um avanço técnico voraz mais a serviço da destruição do que vindo em auxílio dos seres humanos: "Instead of draining rivers, society directs a human stream into a bed of trenches; instead of dropping seeds from airplanes, it drops incendiary bombs" (BENJAMIN, 1992, p. 235).

Fiama partilha desta visão e mostra-o activando ou salvando da ruína do tempo imagens do passado, como a padeira de Aljubarrota, figura assaz aproveitada pela ideologia nacionalista e fascista do Estado Novo português. No "Poema para a padeira que estava a fazer pão enquanto se travava a Batalha de Aljubarrota", do já citado livro Barcas Novas (1967), o contraste é entre a guerra (destruição) e a paz (produção, mesa, partilha, pão).

Lá de fora entram armas

os homens

As mãos dela não repousam

acolhem

Sobre a mesa pôs o pão

arma de paz

Contra as armas da batalha

arma de mão

Contra a batalha das armas

não repousa

Caem contra a mesa os mortos

contra o forno 


\author{
Outra paz não defende ela \\ que a do pão \\ Defende a paz que é da casa \\ e das mãos \\ (BRANDÃO, 2006, p. 33)
}

Parece-nos haver uma convergência entre a visão do passado proposta por Fiama e o pensamento de Benjamin que nas suas teses sobre o conceito de história tenta desconstruir um historicismo linear ao serviço dos vencedores, defendendo, antes, que "History is the subject of a structure whose site is not homogeneous, empty time, but time filled by the presence of the now [Jetztzeit]. Thus, to Robespierre, ancient Rome was a past charged with the time of now which he blasted out of the continuum of history" (BENJAMIN, 1992, p. 252), e apontado algumas formas de recuperar as ruínas da história que o progresso nos tenta ocultar: "historical materialism cannot do without the notion of a present which is not a transition, but in which time stands still and has come to a stop". (BENJAMIN, 1992, p. 254).

É interessante deixar no ar uma questão como uma ponta solta: não será, talvez, o "leitor único" buscado por Fiama ${ }^{4}$ o contraponto da reprodução mecânica que «substitutes a plurality of copies for a unique existence" (BENJAMIN, 1992, p. 215). Ou seja: uma transposição da aura do objecto para o leitor? Leia-se em Benjamin: "In permitting the reproduction to meet the beholder or listener in his own particular situation, [the technique of reproduction] reactivates the object reproduced" (BENJAMIN, 1992, p. 215). Podemos ainda considerar que o hermetismo ou, melhor, essa aparição fulgurante de uma erudição invulgar nos poemas de Fiama poderá ser vista como uma estratégia de distanciamento entre o sujeito poético e o próprio objecto poético, procurando uma leitura mais contemplativa, recusando anular a individualidade e a experiência única do leitor (como na famosa citação de Raymond Williams, "There are in fact no masses, but only ways of seeing people as masses") (WILLIAMS, 1989, p. 77), pedindo em troca uma leitura atenta: "Distraction and concentration form polar opposites which may be stated as follows: A man

\footnotetext{
${ }^{4} \mathrm{~A}$ temática do leitor único é abordada em numerosos poemas de Brandão, como "A voz da rã", citado neste ensaio (BRANDÃO, 2006, p. 652-655), e vem sendo abordada por Jorge Fernandes da Silveira nas suas pesquisas e nomeadamente no ensaio "Dia Fiama: um testemunho", recolhido na Revista Diadorim em homenagem a Fiama Hasse Pais Brandão (2018).
} 
who concentrates before a work of art is absorbed by it. [...] In contrast, the distracted mass absorbs the work of art" (BENJAMIN, 1992, p. 232).

A convocação dessa contemplação ocorre muitas vezes no encontro com a natureza, ou melhor, com as imagens da natureza. Embora Fiama não seja uma flâneuse como Benjamin, ou Baudelaire, é na natureza ou na convocação da natureza que procura uma cisão do espaço urbano: "the sight of immediate reality has become an orchid in the land of technology" (BENJAMIN, 1992, p. 232). Trata-se de uma natureza apreendida por meio da cultura - o que vemos é escrito depois de ter sido descrito por outros:

\begin{abstract}
Depois de estar descrita, a realidade torna-se vital e os seres naturais como o touro e a sombra dependem de todas as imagens.
\end{abstract}

Estar no subúrbio permite-me imediatamente ter o prazer da cultura, chegar a uma janela vendo o claro escuro de um campo nacional na tela, com o amamentar dos pequenos vitelos dentro de molduras de ouro velho.

Não é tão estranha a vitalidade da Natureza quando as paisagens são cópias

quanto é estranha e simples sempre que a humanidade as considera reais.
$[\ldots]$
(BRANDÃO, 2006, p. 280)

A linguagem, o acto de nomeação, é criador por recuperar correspondências antigas. Não podemos escapar à linguagem, que nos chega até pelo leite materno: "O leite, bebida argêntea cheia de signos / que passa de geração em geração / até à sua metamorfose num texto como este", versos que evocam as palavras de Samuel Usque justificando ter escrito o seu livro em Português e não castelhano: "porque desconveniente era fugir da língua que mamei."

\footnotetext{
${ }^{5}$ Judeu português exilado em Ferrara, Itália, onde publicou em 1553, na impressora de seu irmão, Abraão Usque, a sua obra Consolação às Tribulações de Israel. Note-se que Menina e Moça, de Bernardim Ribeiro foi publicada pelo mesmo impressor; estas ligações entre o misticismo judaico e a literatura peninsular foram exploradas não só por Fiama na obra já citada, mas também por outros autores portugueses, sendo igualmente discutidas por Scholem na sua obra Major Trends in Jewish Mysticism.
} 
Mas essa nomeação é não só "homenagemàliteratura", ${ }^{6}$ certamente, mas uma homenagem a tudo o que foi "espezinhado", como diz um poema de Cantos do Canto (1995): "o escaravelho cai na mão do Amado / e à sua direita tem o seu lugar / quando for espezinhado pelo algoz / que não esteja possuído pelo fascínio". Aquilo que se tornou quase esquecido no avançar do tempo e na sofreguidão do "progresso" humano Fiama visa a recuperar, nesta e noutras histórias recolhidas por Fiama nos ensaios de Camões e o Labirinto Camoniano.

\subsection{Cantar o tempo que magoa} suspeição:

$\mathrm{O}$ encontro de um real com imagens já ditas cria na poeta uma NO LARANJAL

O caseiro tem um lugar cativo que não é o da memória, mas o da suspeita tal como os lugares dos vivos. Por exemplo, se tu estás, vejo-te porque suspeito de que a tua presença veio. Suspeito de mim porque te reconheci $[\ldots]$ (BRANDÃO, 2006, p. 631)

Há uma validação ontológica (não absoluta) nesse encontro com o outro, esteja o outro vivo ou morto. Um encontro que vai para além de uma evocação pela memória, é um encontro com uma aparição, uma fantasmagoria do passado:

[...] Tu, meu amante morto,

vieste também, porque há tanto tempo suspeito

de que a tua presença, agora insubstancial

não caberia nunca na memória. Fosses tu

um homem dos ofícios rurais, e ainda habitarias

os campos, não, nunca, na memória, mas aqui.

(BRANDÃO, 2006, p. 631)

O ser poético entrega-se à fulguração da aparição das coisas: "Quando rebenta a flor nova no/ alpendre da casa, parte de mim/ entrega-

\footnotetext{
${ }^{6}$ Expressão com que Fiama Hasse Pais Brandão intitula um de seus livros, dos anos 1970, em que faz o mencionado rol de seu próprio cânone literário, principalmente da literatura portuguesa, que a influenciou.
} 
se à aparição" (BRANDÃO, 2006, p. 324), tentando assim reencontrar uma referência topológica para a posição do ser e do seu contexto, sempre sobre ameaça: "Vai chegar a manhã espessa cheia de lodo leve/ para apagar os vestígios da posição das coisas (BRANDÃO, 2006, p. 325)".

A nossa aprendizagem do ver e da representação linguística e cultural das imagens vistas ou ouvidas parece assentar em coincidências/ correspondências. No poema já citado "Peregrinação e Catábase", podemos observar que Fiama localiza a ação num espaço temporal "depois da noite" do século, conhecida como a Segunda Guerra Mundial, e mais adiante faz uma referência ainda mais precisa: "Era no meio do século", logo que passado o horror da guerra. Essas referências aproximam o poema ainda mais não só ao contexto biográfico de Benjamin e do seu fim trágico, mas também do contexto histórico-cultural subjacente à sua obra:

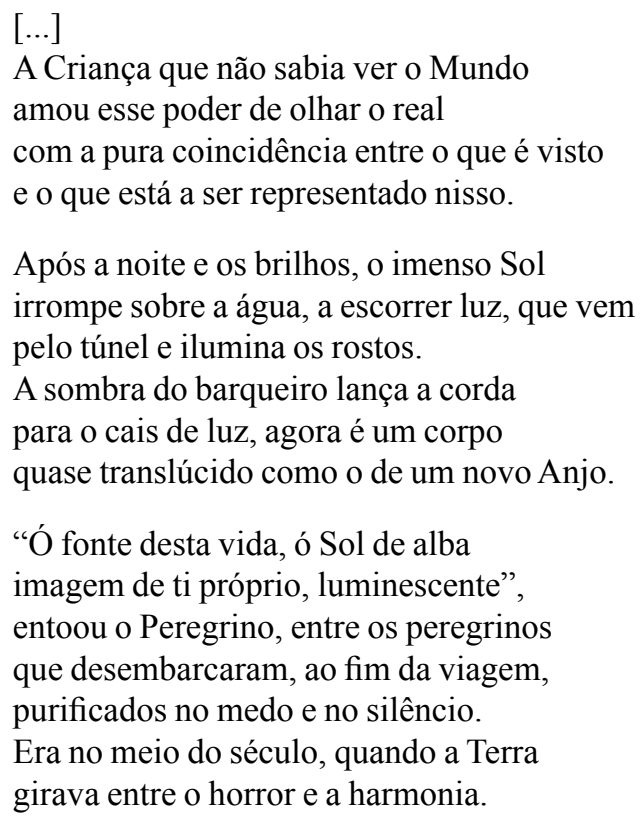

(BRANDÃO, 2006, p. 691)

O barqueiro que possibilita a passagem do Peregrino por diferentes tempos surge como um Anjo trazendo a luz, diferente do anjo melancólico descrito por Benjamin nas suas teses sobre o conceito de história. Neste 
longo poema é o sujeito poético que passa a se identificar com a Criança, e se aproxima dessa alegoria do Anjo da História: ${ }^{7}$

Sou eu que sou Criança, então, que vejo a imensa massa dos peregrinos e o Homem que veio do fulgor das cidades da Europa, com a roupa rota, o cajado na mão, a miragem e a esperança no seu espírito. $[\ldots]$

Foi no meio do século que vi os peregrinos de rastos, de mãos postas, de pés nus, à minha roda, e o Mundo a gemer.

Como podem andar o choro, a doença, a dor? Como vêm por estas estradas, a arrastar-se, mulheres encurvadas que puxam os filhos e os homens a carga do pão?

Vieram um a um, e grupo a grupo, por terras de fartura que, tal como as cidades, vão secar despois no fim do século. Todos têm consigo a sua dor e a dor futura.

Ela, a Criança, viu-os na infância e não soube quanta amargura e quanta dor em si traziam os peregrinos vivos. (BRANDÃO, 2006, p. 685).

Walter Benjamin não terá sido, então, um dos peregrinos destes versos, que evocam imagens da destruição provocada pela Segunda Guerra Mundial? O final desse poema, assim, remontará ao Anjo da História, uma leitura benjaminiana da obra Angelus Novus, de Paul Klee, ou "novo Anjo", como aparece no poema de Fiama:

Após a noite e os brilhos, o imenso Sol irrompe sobre a água, a escorrer luz, que vem pelo túnel e ilumina os rostos.

A sombra do barqueiro lança a corda para o cais de luz, agora é um corpo quase translúcido como o de um novo Anjo.

7 "This is how one pictures the angel of history. His face is turned toward the past. Where we perceive a chain of events, he sees one single catastrophe which keeps piling wreckage upon wreckage and hurls it in front of his feet." (BENJAMIN, 1992, p. 249). 
"Ó fonte desta vida, ó Sol de alba imagem de ti próprio, luminescente", entoou o Peregrino, entre os peregrinos que desembarcaram, ao fim da viagem, purificados no medo e no silêncio.

Era no meio do século, quando a Terra girava entre o horror e a harmonia.

(BRANDÃO, 2006, p. 692)

O anjo, por sua vez, é descrito desta maneira por Walter Benjamin nas suas Teses sobre a História:

His eyes are staring, his mouth is open, his wings are spread. This is how one pictures the angel of history. His face is turned toward the past. Where we perceive a chain of events, he sees one single catastrophe which keeps piling wreckage upon wreckage and hurls it in front of his feet. [...] The angel would like to stay, awaken the dead, and make whole what has been smashed.

(BENJAMIN, 1992, p. 249)

A palavra, que em certas fases da obra de Fiama, tinha o poder demiurgo do anjo, de "awaken the dead, and make whole what has been smashed" (BENJAMIN, 1992, p. 249), que podia amanhecer o próprio dia, como no poema "O nome lírico", citado adiante neste artigo, passa agora a criar essa vidraça onde embatem os sinais vindos da história. Esses sinais dispersos, unidos por toda a cultura agregada nos poemas, pelas palavras da poeta, palavras do morto, vão, linha a linha, unindo o que no real está disperso. Isto é, o poema cria a coisa a que chamamos universo, onde vamos em cadeiras e mesas de verga efémeras, "girando nas grandes nebulosas", como num trecho do "Canto da chávena de chá":

as palavras movem-se e repõem

no seu imóvel eixo de rotação

o espaço onde esta mesa de verga

gira nas grandes nebulosas. (BRANDÃO, 2006, p. 573)

Pelas suas visões, mostradas como transes alucinatórios no verso, o sujeito poético resiste à ameaça da ruína, à extinção da fala: 


\author{
[...] Trepadeiras confusas \\ parecem muros. Estas visões \\ evitam que a casa se destrua. Sou o sujeito \\ que imagina o pensamento dessa figura \\ comparada a uma ruína.
}

A que floresce com o vulto da primavera

há-de deteriorar-se na penumbra

que vai ruir. Terá a vida própria

de um conceito. A porta que dá para o caos.

(BRANDÃO, 2006, p. 324)

O sujeito poético ocupa esse espaço onde a vida que se esvai tenta ancorar-se no que consegue recuperar do mundo que as ferramentas do progresso que alucina, altera e oprime esse sujeito com os seus "sound and fury", parafraseando Shakespeare, como no poema "O começo da obra":

Esta obra está em ruínas. Um silêncio

entre-dentes. Calaram-se. As ferramen

tas não gemem. Dormi e não estou.

Morro mas vivo. Os materiais

transcendem-me e o tempo bebe-

me.

(BRANDÃO, 2006, p. 408)

\title{
2. A paisagem (i)móvel
}

Tanto Fiama quanto Walter Benjamin concordam com o facto de que a arte e o contexto histórico alteram a percepção sensorial: "the fifth century [...] developed not only an art different from that of antiquity but also a new kind of perception" (BENJAMIN, 1992, p. 216). Fiama tenta dar-nos essa ideia nas suas referências e evocações de pintores, perplexa e/ou emocionada pela percepção implícita nas suas imagens. Essa aproximação muitas vezes a outros tempos históricos, frequente na poeta, tem o poder revolucionário, de colocar em contato duas diacronias, numa paradoxal sincronia atemporal, tal como defende Benjamin, nas "Theses on the Philosophy of History". Esta configuração, fora do fluxo destruidor do tempo, de dois momentos distintos, uma época passada assim erguida da ruína com um tempo presente, encontra um símile na molécula que se liga à enzima, activando uma série de reacções que de outra forma não ocorreriam. 
Podemos ler, nesta linha, que dessa forma Fiama tece uma estratégia de recuperação ou invocação da aura do objecto, pedindo ao leitor uma nova perceção das imagens da sua poesia, que, embora consciente da sua autoproclamada ruína e futilidade, não abandona o poder transformador do ser e da posição deste ser no mundo. É importante realçar a presença das imagens da Natureza e sua relação com o sujeito poético que parecem ecoar tentativas de recuperar essa experiência de aura. Benjamin define a aura dos objectos naturais como "the unique phenomenon of a distance, however close it may be" (BENJAMIN, 1992, p. 216). A isso se opõe o desejo das massas de "bring things 'closer' spatially and humanly, which is just as ardent as their bent toward overcoming the uniqueness of every reality by accepting its reproduction" (BENJAMIN, 1992, p. 217).

Fora dessa roda amnésica da história, surgem personagens em configurações próximas ao Anjo da História - mas não com um olhar tridimensional: além do passado e do futuro e do ponto presente em que se encontra e se encontra o sujeito poético que nunca recusa ser o observador do seu tempo, acrescenta-se que esse olhar dual do anjo é ele mesmo uma herança, uma recuperação acumulada de anteriores olhares (messiânicos ou não) que insuflam a existência ou as visões de algo (lembremos do título de 1975, Novas Visões do Passado), contanto que sejam novas. Fiama também reivindicará a presença de barcas novas, que contrastem com as do cancioneiro português de Joan Zorro, assim como com aquelas barcas que no início dos anos 1960 iam sendo "metidas ao mar" para o avanço da guerra colonial. Assim, a produção de novas visões para a poesia alcança uma renovação de imagens que recuperam o que se pensava eliminado pela História. Igualmente, recupera-se o que se esvai no fluxo do tempo para esse não tempo, em que tudo termina: a história, a literatura, os astros das nossas percepções.

\subsection{Dialética impossível}

Em Fiama Hasse Pais Brandão há essa consciência intensa, pavimentada pela filosofia de Walter Benjamin, de que somos seres a caminho da catástrofe, avançando sobre ruínas. No caso da poeta, isso se demonstra pela via dos sentidos: seja ela a partir da alucinação da visão ou das consciências corpóreas, conforme já se indicou nas páginas anteriores. A própria fórmula usada para descrever essa catábase é metáfora da ruína deixada pelos mortos (nas formas de homenagem, epitáfio e messianismo). Como podemos nos apropriar dos cacos da 
linguagem para criar configurações que anulem neutralizem este jugo do tempo? Fiama aceita que nem a linguagem nem as imagens salvam. Que há um mundo impermeável ao dizer. Mas dizer, inclusive o indizível, pode erguer um mundo.

Que olhares e sons nos chegam de Walter Benjamin? Os objectos auráticos se depositam, poalha dos tempos, na nossa pele. Como viver entre ruínas, que fazer com os sentidos (vista, audição, olfacto, tacto) quanto tudo é perecível? Que fazer quando os humanos, marcando no globo seus passos, avançam para a catástrofe, quando os humanos são quase todos armas se entre-matando?

De acordo com Fiama não podemos escapar à transmissão da linguagem e do mundo que ela traz. Por outro lado, nessa mesma poesia, essa relação parece ter perdido a sua autoridade, o seu poder - inclusive o seu poder de nomeação ou denotação. As coisas já não podem ser nomeadas, revestem-se apenas do "eco das palavras" (BRANDÃO, 2006, p. 715), mas até esse processo é suspeito, como visto anteriormente.

Estamos presos no mundo que nos foi transmitido, é um mundo de morte, de ruínas, deixado pelos que já partiram - por isso o sujeito poético tem essa aguda percepção da impermanência das coisas, da sua finitude, da insignificância da palavra, da escrita "toda a literatura será perdida", ${ }^{8}$ de modo que as próprias palavras transmitem o seu fim... que posição pode o poeta ocupar perante isso? Não há valores de verdade, e de acordo com Benjamin nem a história pode ser vista de outra maneira que não a melancólica, concebida como "catástrofe e acúmulo de ruínas". Da mesma forma que a melancolia pessoal pode ser transposta para uma leitura da história, tal concepção não pode também ser devolvida para o "âmbito da vida pessoal? Que mais será a vida pessoal senão catástrofe, acúmulo de ruínas, fragmentação, fracassos, abandonos, sensação generalizada de perda de objetos e de sentidos supostamente superiores?" (BORGÉA, 2018, p. 9). Em resposta lateral, insuficiente, a esses anseios desanimadores, as palavras estão à disposição para produzir alucinações auditivas visuais: erguem dias depois de erguerem a custo um canto: "Esta manhã/ hoje/ é um nome [...]// Uma palavra/ palavra só/ a ergue// Com um nome/ amanhece/ clareia" (BRANDÃO, 2006, p. 49).

Em conclusão, poderíamos dizer que em Fiama o presente é a pira em que queimam as ruínas do passado - a chama que avança sobre a terra em direção a esse fim futuro, o abraço fatal solar: chama ardendo

8 “A voz da rã”, Cenas Vivas (2000) (BRANDÃO, 2006, p. 654) 
em pira final, metáfora desse amor que não pode ser descrito senão por uma correspondência metafórica com a experiência do mundo natural sobre o corpo:

Por vezes, o mundo cala-se.

Nos crepúsculos, sobretudo.

Há horas em que o olhar

se expande, alheio, e não estremece ao ver a predadora gaivota rasgar a presa, o último alimento do seu dia.

\section{O mundo}

cala-se, e nem a vítima

sacode com ruído a água.

A vencedora, apenas,

paga o débito aos meus olhos, ondulando as asas, para longe,

para o nada, já sem a luz do Sol

ou com o Sol nascente, em vez de mim.

(BRANDÃO, 2006, p. 620)

\section{Referências}

BENJAMIN, Walter. The Work of Art in the Age of Mechanical Reproduction. In: ARENDT, Hannah (ed.). Illuminations. Transl. H. Zohn. Londres: Fontana Press, 1992. p. 211-244.

BLANCHOT, Maurice. O livro por vir. São Paulo: Martins Fontes, 2005. BOGÉA, Diogo. Melancolia, catástrofe, ruína: considerações sobre história e vida em Walter Benjamin. Revista Sísifo, [S.l.], 2018. Disponível em: http://www.revistasisifo.com/2018/05/melancolia-catastrofe-ruina. html. Acesso em: 30 set. 2019.

BRANDÃO, Fiama Hasse Pais. Obra Breve. Lisboa: Assírio \& Alvim, 2006.

KOTHE, Flávio R. A aura. In: . Para ler Benjamin. Rio de Janeiro: Francisco Alves, 1976. p. 39-41.

WILLIAMS, Raymond. Culture is Ordinary. Resources of Hope. In: . Resource of Hope: Culture, Democracy, Socialism. Londres: Verso, 1989. e-book. 